\title{
Synthesis and Characterization of Polybinaphthyls Incorporating Chiral $(R)$ or $(S)$-2,2'-Binaphthyl Entities by Heck Reaction
}

\author{
Yixiang Cheng, ${ }^{\dagger}$ Lingwu ChEn, Jinfeng Song, Xiaowei Zou, and Tiandong LiU \\ College of Chemistry and Chemical Engineering, Nanjing University, Nanjing 210093, People's Republic of China
}

(Received November 29, 2004; Accepted February 3, 2005; Published May 15, 2005)

\begin{abstract}
Four chiral conjugated polymer-1 (P-1), polymer-2 (P-2), polymer-3 (P-3) and polymer-4 (P-4) were obtained by the polymerization of $(S)$-6, $6^{\prime}$-dibromo-2,2'-bisbutoxy-1,1'-binaphthyl $((S)$-M-1) and $(R)$-6,6'-dibromo2,2'-bisbutoxy-1,1'-binaphthyl ((R)-M-1) with 1,4-divinyl-2,5-dibutoxybenzene (M-2) and 1,3,4-oxadiazole-2,5bis(4-vinylbenzene) (M-3) under Pd-catalyzed Heck reaction respectively. Both monomers $(S)$-M-1, $(R)-\mathbf{M}-1, \mathbf{M}-2$, M-3 and polymers were analyzed by NMR, MS, FT-IR, UV, fluorescent spectroscopy, polarimetry, GPC, circular dichroism (CD-) spectra. Four polymers can emit stronger green-blue fluorescence and are expected to have the potential application in the polarized light-emitting sensors. [DOI 10.1295/polymj.37.355] KEY WORDS (R)- and $(S)-1,1^{\prime}$-Binaphthol / Chiral Polymers / Fluorescence / Heck Reaction /
\end{abstract}

Chiral conjugated polymers are optically active materials made of organic fragments such as aromatic rings and unsaturated carbon or heteroatom bonds with delocalizable $\pi$-electronic system. ${ }^{1-4}(R)$ or $(S)$ $1,1^{\prime}$-binaphthol (BINOL) have often been used as the starting materials for obtaining chiral binaphthyl compounds. The 2,2'-hydroxyl groups of BINOL can be easily converted into other functional groups and the 3,3'-and 6,6'-positions of binaphthyl skeletal structure of BINOL can be selectively functionalized at the well-defined molecular level, leading to a variety of binaphthyl derivatives which can exhibit remarkably stable chiral configuration as well as high chiral induction in molecular recognition, ${ }^{5-9}$ asymmetric processes. ${ }^{10-15}$ These rigid and sterically chiral polybinaphthyl polymers also represent a new generation of materials for applications in chiral sensors, polarized light emission and nonlinear optical materials. ${ }^{16-20}$

Conjugated polymers with rigid $\pi$-systems often possess poor solubility, which seriously inhibits full structural elucidations and property investigations. We choose M-2 and M-3 as the conjugated molecular bridge linkers. Oxadiazole derivatives have been widely used as electron transporting/hole blocking materials in LED devices and LED blends because oxadiazole unit has many excellent properties on the better chromophore, high thermal and oxidative stability, and the good charge injection and transporting building blocks. ${ }^{21-23}$ In our paper, M-3, 1,3,4-oxadiazole2,5-bis(4-vinylbenzene) is introduced into the chiral polymers main chain backbone to maintain conjugation between the oxadiazole and binaphthyl segments so that the electron transporting properties of the poly- mers may be improved. In addition, by introducing oxadiazole, an electron deficient moiety into the main chain, the electron density may shift away from the vinyl bond, which could increase the stability of the resulting chiral polymers. ${ }^{24,25}$ To make soluble conjugated polymers, the alkyl groups substitutents on the phenyl and binaphthyl rings as side chain of the polymers can improve solubility in organic solvents and facile electro-optical sensors. Heck, Suzuki, Stille and Sonogashira reactions are the most important $\mathrm{C}-\mathrm{C}$ coupling reactions in organic chemistry synthesis. Herein, we present preliminary results of synthesis and properties of four polymers based on the chiral unit $1,1^{\prime}$-binaphthyl structure. The four chiral polymers containing vinylene linkages between naphthyl and phenyl groups can reduce steric hindrance between backbone rings and groups, and also have a beneficial effect on delocalizable $\pi$-electronic conjugation structure of polymers. These polymers are green-blue light emitting materials with very good fluorescence quantum efficiencies.

\section{EXPERIMENTAL}

\section{General}

${ }^{1} \mathrm{H},{ }^{13} \mathrm{C}$ NMR spectra measurements (all in $\mathrm{CDCl}_{3}$ ) were recorded on a 300-Bruker spectrometer with TMS as internal standard. FT-IR spectra were taken in $\mathrm{KBr}$ plates on Nicolet-170SX spectrometer. UVvis spectra were carried out on PerkinElmer Lambda 25. Fluorescent spectra were carried out on 48000 DSCF spectrometer. MS was determined on Micromass GCT. Elemental analyses were carried out by

${ }^{\dagger}$ To whom correspondence should be addressed (Tel: +86-25-83592709, Fax: +86-25-83317761, E-mail: yxcheng@nju.edu.cn). 
HN-O-RAPID instrument. Circular dichroism (CD-) spectra were carried on JASCO J-810 spectropolarimeter. Molecular weight was determined by gel permeation chromatography (GPC) on Waters-244 HPLC pump and THF used as solvent and relative to polystyrene standards. All solvents and reagents were purchased from commercial A.R. grade. All reactions were performed under nitrogen atomosphere using Schlenk tube techniques. In experiments requiring dried solvents, THF and toluene was distilled from sodium-benzophenone, DMF was distilled from $\mathrm{CaH}_{2}$, and $\mathrm{CH}_{2} \mathrm{Cl}_{2}$ was distilled from $\mathrm{P}_{2} \mathrm{O}_{5}$.

\section{Monomer Syntheses}

Preparation of (S)-6,6'-Dibromo-2,2'-dibutoxy-1,1'binaphthyl ((S)-M-1). A mixture of (S)-6,6'-dibromo1,1'-binaphthol (6.08 g, $13.7 \mathrm{mmol}), \mathrm{K}_{2} \mathrm{CO}_{3}(14 \mathrm{~g}, 0.1$ $\mathrm{mol})$ and 1-bromobutane $(6.48 \mathrm{~g}, 48.6 \mathrm{mmol})$ in 180 $\mathrm{mL} \mathrm{CH} \mathrm{CN}_{3} \mathrm{CNas}$ refluxed for $4 \mathrm{~h}$ under $\mathrm{N}_{2}$. The second portion of $\mathrm{K}_{2} \mathrm{CO}_{3}(7 \mathrm{~g}, 0.05 \mathrm{~mol})$ and 1-bromobutane $(3.24 \mathrm{~g}, 24.3 \mathrm{mmol})$ was added to ensure the complete reaction. The solution was stirred and continued to keep refluxing for $10 \mathrm{~h}$. The mixture was poured into $5 \%$ aqueous $\mathrm{NaOH}(200 \mathrm{~mL})$. The solution was extracted by ethyl acetate $(150 \mathrm{~mL})$. The organic layer was washed with saturated brine for two times and then dried over anhydrous $\mathrm{MgSO}_{4}$. After the solvent was removed under the reduced pressure, the residue was purified by chromatography on silica with petroleum ether as eluent. $(S)$-M-1 was obtained as a pale yellow viscous product in $98 \%$ yield $(7.46 \mathrm{~g}) .[\alpha]_{\mathrm{D}}=$ -19.5 (c = 0.1, THF); ${ }^{1} \mathrm{H}$ NMR $\left(300 \mathrm{MHz}, \mathrm{CDCl}_{3}\right)$ : $\delta 0.68(\mathrm{t}, 6 \mathrm{H}, J=7.36 \mathrm{~Hz}), 1.03(\mathrm{~m}, 4 \mathrm{H}), 1.43(\mathrm{~m}$, $4 \mathrm{H}), 3.98(\mathrm{~m}, 4 \mathrm{H}), 7.01(\mathrm{~d}, 2 \mathrm{H}, J=9.00 \mathrm{~Hz}), 7.27(\mathrm{dd}$, $2 \mathrm{H}, J=9.01,2.01 \mathrm{~Hz}), 7.43(\mathrm{~d}, 2 \mathrm{H}, J=9.00 \mathrm{~Hz})$, $7.86(\mathrm{~d}, 2 \mathrm{H}, J=9.00 \mathrm{~Hz}), 8.02(\mathrm{~d}, 2 \mathrm{H}, J=1.94 \mathrm{~Hz})$; ${ }^{13} \mathrm{C}$ NMR $\left(300 \mathrm{MHz}, \delta \mathrm{CDCl}_{3}\right): 13.49,18.70,31.25$, 69.17, 116.37, 117.17, 120.02, 127.09, 128.35, 129.40, $129.72,130.16,132.57,154.76 ; \delta v_{\max }(\mathrm{KBr}) / \mathrm{cm}^{-1}$ : $2956.6,2930.9,1584.1,1493.2,1327.7,1269.2$, 1244.1, 1070.5, 875.0, 809.3.

Preparation of (R)-6,6'-Dibromo-2,2'-dibutoxy1,1'-binaphthyl ((R)-M-1). (R)-M-1 was synthesized as the same procedures of $(S)-\mathbf{M}-\mathbf{1}$, and the final yield was $96 \%,[\alpha]_{\mathrm{D}}=+18.8(\mathrm{c}=0.1$, THF $) ;{ }^{1} \mathrm{H}$ NMR $\left(300 \mathrm{MHz}, \mathrm{CDCl}_{3}\right): \delta 0.68(\mathrm{t}, 6 \mathrm{H}, J=7.37 \mathrm{~Hz}), 1.02$ $(\mathrm{m}, 4 \mathrm{H}), 1.42(\mathrm{~m}, 4 \mathrm{H}), 3.97(\mathrm{~m}, 4 \mathrm{H}), 6.99(\mathrm{~d}, 2 \mathrm{H}$, $J=9.04 \mathrm{~Hz}), 7.28(\mathrm{dd}, 2 \mathrm{H}, J=9.00,2.02 \mathrm{~Hz}), 7.42$ $(\mathrm{d}, 2 \mathrm{H}, J=9.03 \mathrm{~Hz}), 7.85(\mathrm{~d}, 2 \mathrm{H}, J=9.01 \mathrm{~Hz}), 8.02$ $(\mathrm{d}, 2 \mathrm{H}, J=1.92 \mathrm{~Hz}) ; \delta v_{\max }(\mathrm{KBr}) / \mathrm{cm}^{-1}: 2957.0$, $2931.4,2870.7,1584.9,1493.7,1327.9,1270.0$, 1242.9, 1070.3, 875.8, 807.9.

Preparation of 1,4-Dibutoxybenzene (1). A mixture of hydroquinone ( $5 \mathrm{~g}, 45.4 \mathrm{mmol}), 1$-bromobutane $(13.7 \mathrm{~g}, 100 \mathrm{mmol})$ and $\mathrm{NaOH}(4.8 \mathrm{~g}, 120 \mathrm{mmol})$ in
$50 \mathrm{~mL}$ ethanol was refluxed $12 \mathrm{~h}$ under $\mathrm{N}_{2}$ and then poured into water. The precipitate was filtered and washed with water $(3 \times 100 \mathrm{~mL})$. The crude solid was recrystalized from $95 \%$ ethanol $(2 \times 60 \mathrm{~mL})$ to give a white product 1 in $82 \%$ yield $(8.3 \mathrm{~g})$. Mp: $49-51{ }^{\circ} \mathrm{C}$; ${ }^{1} \mathrm{H} \mathrm{NMR}\left(\mathrm{CDCl}_{3}\right): \delta 0.99(\mathrm{t}, 6 \mathrm{H}, J=7.4 \mathrm{~Hz}), 1.44$ $1.57(\mathrm{~m}, 4 \mathrm{H}), 1.72-1.81(\mathrm{~m}, 4 \mathrm{H}), 3.93(\mathrm{t}, 4 \mathrm{H}, J=$ $6.5 \mathrm{~Hz}), 6.85(\mathrm{~s}, 4 \mathrm{H}) ; v_{\max }(\mathrm{KBr}) / \mathrm{cm}^{-1}: 1511.07$, $1472.13, \quad 1399.24, \quad 1288.90, \quad 1239.26, \quad 1123.60$, 1072.15, 1043.19, 1013.90, 974.16, 828.42.

Preparation of 1,4-Bis(bromomethyl)-2,5-dibutoxybenzene (2). A mixture of $1(4 \mathrm{~g}, 18 \mathrm{mmol}),(\mathrm{HCHO})_{\mathrm{n}}$ $(3 \mathrm{~g}, 180 \mathrm{mmol})$, saturated aqueous $\mathrm{HBr}(8 \mathrm{~mL})$ and $\mathrm{H}_{3} \mathrm{PO}_{4}(4 \mathrm{~mL})$ in $50 \mathrm{~mL} \mathrm{AcOH}$ was heated to $90^{\circ} \mathrm{C}$ for $3 \mathrm{~h}$ under $\mathrm{N}_{2}$, and then the mixture was poured into water $(300 \mathrm{~mL})$. The precipitate was filtered and washed by water $(3 \times 200 \mathrm{~mL})$ and recrystalized over petroleum ether to give a white product 2 in $76 \%$ yield $(5.60 \mathrm{~g}) . \mathrm{Mp}:{ }_{108}-110^{\circ} \mathrm{C} ;{ }^{1} \mathrm{H}$ NMR $(300 \mathrm{MHz}$, $\left.\mathrm{CDCl}_{3}\right): \delta 1.01(\mathrm{t}, 6 \mathrm{H}, J=7.4 \mathrm{~Hz}), 1.49-1.63(\mathrm{~m}$, 4H), 1.77-1.87 (m, 4H), 4.55 (s, 4H), 6.87 (s, 2H).

Preparation of 1,4-Divinyl-2,5-dibutoxybenzene $(\boldsymbol{M}-2)$. A solution of $2(4 \mathrm{~g}, 9.75 \mathrm{mmol})$ and triphenylphosphate $(5.6 \mathrm{~g}, 21.4 \mathrm{mmol})$ in $40 \mathrm{~mL}$ toluene was refluxed for $4 \mathrm{~h}$ and produced $3(8.4 \mathrm{~g})$. The precipitate was filtered and washed with petroleum ether, and then transferred into a $100 \mathrm{~mL}$ three-necked flask for M-2 synthesis. A mixture of $\mathrm{CH}_{2} \mathrm{Cl}_{2}(30 \mathrm{~mL})$ and aqueous $\mathrm{HCHO}(12 \mathrm{~mL})$ were added into the former flask. The solution was cooled down to $-15^{\circ} \mathrm{C}$ and stirred vigoriously. $10 \%$ aqueous $\mathrm{NaOH}(20 \mathrm{~mL})$ was added dropwise over $1 \mathrm{~h}$ with constant stirring under $\mathrm{N}_{2}$. The resulting mixture was stirred at room temperature overnight, and then $50 \mathrm{~mL}$ water was added to the above solution. The resulting solution was extracted three times with dichloromethane $(20 \mathrm{~mL})$. The combined organic layers were washed with saturated brine twice and dried over anhydrous $\mathrm{MgSO}_{4}$. The solvent was removed to dryness under the reduced pressure. The colorless crystal product M-2 was obtained as a colorless crystal in 63\% yield $(1.69 \mathrm{~g})$ by the recrystallization of $50 \%$ ethanol twice. Mp: $42-44{ }^{\circ} \mathrm{C} ;{ }^{1} \mathrm{H}$ NMR $\left(300 \mathrm{MHz}, \mathrm{CDCl}_{3}\right): \delta 1.01(\mathrm{t}$, $6 \mathrm{H}, J=7.4 \mathrm{~Hz}), 1.48-1.61(\mathrm{~m}, 4 \mathrm{H}), 1.77-1.86(\mathrm{~m}$, $4 \mathrm{H}), 4.00(\mathrm{t}, 4 \mathrm{H}, J=6.4 \mathrm{~Hz}), 5.28(\mathrm{dd}, 2 \mathrm{H}, J=10.9$, $1.3 \mathrm{~Hz}), 5.76(\mathrm{dd}, 2 \mathrm{H}, J=17.7,1.3 \mathrm{~Hz}), 7.01(\mathrm{~s}, 2 \mathrm{H})$, $7.10(\mathrm{dd}, 2 \mathrm{H}, J=8.9,6.6 \mathrm{~Hz}) ;{ }^{13} \mathrm{C}$ NMR $(300 \mathrm{MHz}$, $\left.\mathrm{CDCl}_{3}\right): \delta 14.31,19.78,30.11,31.95,69.39,110.90$, $114.40,127.57,131.94,151.03 ; v_{\max }(\mathrm{KBr}) / \mathrm{cm}^{-1}$ : $2959.1,2934.1,2871.8,1621.6,1497.8,1425.7$, 1378.9, 1204.6, 1068.5, 1027.4, 994.3, 903.2; MS $m / z: 274\left(\mathrm{M}^{+}, 42.56\right), 162$ (100).

Preparation of 2,5-Bis(4-methylbenzene)-1,3,4-oxadiazole (4). A mixture of orthophosphoric acid $(1.5 \mathrm{~mL})$ and phosphorus oxide $(3.3 \mathrm{~g}, 23 \mathrm{mmol})$ was 
heated to $120^{\circ} \mathrm{C}$ under $\mathrm{N}_{2}$. After the solid was dissolved completely, hydrazine sulfate $(0.72 \mathrm{~g}, 5.5$ mmol) and $p$-toluic acid $(1.5 \mathrm{~g}, 11.0 \mathrm{mmol})$ was add$\mathrm{ed}$, and then the mixture was heated to $135^{\circ} \mathrm{C}$ for $8 \mathrm{~h}$. After cooling, the mixture was poured into water. White solid product was precipitated and filtered, the crude product 4 was washed with water, aqueous $\mathrm{NaOH}(\mathrm{pH}=9)$ and water respectively. A yellow crystal was obtained in $76 \%$ yield $(1.05 \mathrm{~g})$. Mp: $173-175^{\circ} \mathrm{C} ;{ }^{1} \mathrm{H}$ NMR $\left(300 \mathrm{MHz}, \mathrm{CDCl}_{3}\right): \delta 2.46(\mathrm{~s}$, $6 \mathrm{H}), 7.35(\mathrm{~d}, 4 \mathrm{H}, J=8.2 \mathrm{~Hz}), 8.04(\mathrm{~d}, 4 \mathrm{H}, J=8.1$ $\mathrm{Hz}) ; v_{\max }(\mathrm{KBr}) / \mathrm{cm}^{-1}: 1614.96,1552.30,1495.61$, 1072.07, 1016.01, 821.45, 735.41.

Preparation of 2,5-Bis(4-bromomethylbenzene)1,3,4-oxadiazole (5). A mixture of $4(0.6 \mathrm{~g}, 2.4$ mmol), $N$-bromosuccinimide $(0.98 \mathrm{~g}, 5.5 \mathrm{mmol})$ and benzoyl peroxide $\left(10 \mathrm{mmg}, 0.04 \mathrm{mmol}\right.$ ) in $10 \mathrm{~mL} \mathrm{CCl}_{4}$ was refluxed for $6 \mathrm{~h}$ under $\mathrm{N}_{2}$. After cooling, the precipitate was filtered, the mixture was washed ether and water. The crude solid $\mathbf{5}$ was recrystalized from $\mathrm{THF} / \mathrm{CH}_{3} \mathrm{OH}(1: 1)$ to give a white product in $57 \%$ yield $(0.55 \mathrm{~g})$. Mp: $225-227^{\circ} \mathrm{C} ;{ }^{1} \mathrm{H}$ NMR $(300 \mathrm{MHz}$, $\left.\mathrm{CDCl}_{3}\right): \delta 4.56(\mathrm{~s}, 4 \mathrm{H}), 7.59(\mathrm{~d}, 4 \mathrm{H}, J=8.3 \mathrm{~Hz})$, $8.14(\mathrm{~d}, 4 \mathrm{H}, J=8.3 \mathrm{~Hz}) ; v_{\max }(\mathrm{KBr}) / \mathrm{cm}^{-1}: 1551.92$, 1493.40, 1227.01, 1072.84, 849.27, 710.95, 598.77.

Preparation of 2,5-Bis(4-vinylbenzene)-1,3,4-oxadiazole (M-3). A mixture of $5(1.4 \mathrm{~g}, 3.43 \mathrm{mmol})$, triphenylphosphate $(2.25 \mathrm{~g}, 8.58 \mathrm{mmol})$ in $20 \mathrm{~mL}$ DMF was refluxed for $10 \mathrm{~h}$ and produced $6(3.5 \mathrm{~g})$. The precipitate was filtered and washed with ether, and then transferred into a $100 \mathrm{~mL}$ three-necked flask for M-3 synthesis. M-3 was synthesized in the same procedures as M-2. The colorless product M-3 yielded $51 \%(0.47 \mathrm{~g})$. Mp: $127-129^{\circ} \mathrm{C} ;{ }^{1} \mathrm{H}$ NMR $(300 \mathrm{MHz}$, $\left.\mathrm{CDCl}_{3}\right): \delta 5.43(\mathrm{~d}, 2 \mathrm{H}, J=10.9 \mathrm{~Hz}), 5.92(\mathrm{~d}, 2 \mathrm{H}, J=$ $17.6 \mathrm{~Hz}), 6.80(\mathrm{dd}, 2 \mathrm{H}, J=17.6,10.9 \mathrm{~Hz}), 7.59(\mathrm{~d}$, $4 \mathrm{H}, J=8.3 \mathrm{~Hz}), 8.12(\mathrm{~d}, 4 \mathrm{H}, J=8.3 \mathrm{~Hz}) ;{ }^{13} \mathrm{C} \mathrm{NMR}$ $\left(300 \mathrm{MHz}, \mathrm{CDCl}_{3}\right): \delta 116.21,123.01,126.78,127.13$, $135.87,140.82,164.36 ; v_{\max }(\mathrm{KBr}) / \mathrm{cm}^{-1}: 1625.1$, 1577.3, 1492.9, 1411.9, 1080.7, 993.3, 901.9, 851.0, 717.9; MS m/z: $274\left(\mathrm{M}^{+}, 82\right), 131$ (100); Elemental anal. (\%) Calcd. For $\mathrm{C}_{18} \mathrm{H}_{14} \mathrm{~N}_{2} \mathrm{O}$ : C 78.81; H 5.14; N 10.21; Found: C 78.67; H 5.17; N 10.05.

\section{Polymer Syntheses}

Preparation of $\boldsymbol{P}-\mathbf{1}$. A mixture of $(S)$-M-1 (382.6 $\mathrm{mg}, 0.688 \mathrm{mmol})$ and $\mathbf{M - 2}(188.5 \mathrm{mg}, 0.688 \mathrm{mmol})$ was dissolved in $8 \mathrm{~mL} \mathrm{DMF}$, and then $2 \% \mathrm{Pd}(\mathrm{OAc})_{2}$ $(3.1 \mathrm{mg}, \quad 0.014 \mathrm{mmol})$ and $6 \%$ triphenylphosphate $(21.7 \mathrm{mg}, 0.083 \mathrm{mmol}), 5$ molar equivalent $\mathrm{Et}_{3} \mathrm{~N}$ $(0.85 \mathrm{~mL}) /(S)$-M-1 were added to the above mixture solution. The solution was stirred and heated at $115^{\circ} \mathrm{C}$ for $10 \mathrm{~h}$ under $\mathrm{N}_{2}$, and then refluxed at $145^{\circ} \mathrm{C}$ for an additional $2 \mathrm{~h}$. The mixture was cooled down to room temperature. The solution was filtered through a short silica gel column into methanol (200 $\mathrm{mL})$ to precipitate out the polymer. The yellow crude polymer was washed with methanol several times. P-1 was dried in vacuo and collected $294.2 \mathrm{mg}$ in $64 \%$ yield. ${ }^{1} \mathrm{H}$ NMR $\left(300 \mathrm{MHz}, \mathrm{CDCl}_{3}\right): \delta 0.66(\mathrm{~m}, 12 \mathrm{H})$, $1.00(\mathrm{~m}, 8 \mathrm{H}), 1.41(\mathrm{~m}, 8 \mathrm{H}), 3.96(\mathrm{~m}, 8 \mathrm{H}), 7.16(\mathrm{~m}$, $2 \mathrm{H}), 7.24(\mathrm{~s}, 2 \mathrm{H}), 7.50(\mathrm{~m}, 6 \mathrm{H}), 7.90(\mathrm{~m}, 6 \mathrm{H}) ;{ }^{13} \mathrm{C}$ NMR $\left(300 \mathrm{MHz}, \mathrm{CDCl}_{3}\right): \delta 13.57,13.95,18.78$, $19.48,31.44,31.64,69.33,69.44,110.58,115.79$, $116.75,120.86,122.76,123.91,125.92,126.66$, $127.08,128.16,129.48,133.25,133.84,151.45$, $154.83 ; v_{\max }(\mathrm{KBr}) / \mathrm{cm}^{-1}: 3048.9,2955.6,2930.7$, $2869.1,1608.5,1589.3,1494.8,1463.7,1272.2$, 1244.8, 1202.6, 1066.3, 1028.1, 964.6.

Preparation of $\boldsymbol{P}-\mathbf{2}, \boldsymbol{P}-\mathbf{3}$ and $\boldsymbol{P}-\mathbf{4}$. $\quad \mathbf{P}-\mathbf{2}, \mathbf{P}-\mathbf{3}$ and $\mathbf{P}-\mathbf{4}$ were synthesized in the same way as $\mathbf{P - 1}$. The yields were $70 \%$ (P-2), 73\% (P-3), 74\% (P-4) respectively. P-4 spectroscopic data: ${ }^{1} \mathrm{H}$ NMR $\left(300 \mathrm{MHz}, \mathrm{CDCl}_{3}\right)$ : $\delta 0.68(\mathrm{~m}, 6 \mathrm{H}), 1.01(\mathrm{~m}, 4 \mathrm{H}), 1.40(\mathrm{~m}, 4 \mathrm{H}), 4.00(\mathrm{~m}$, $4 \mathrm{H}), 7.12(\mathrm{~m}, 2 \mathrm{H}), 7.43(\mathrm{~m}, 4 \mathrm{H}), 7.50(\mathrm{~m}, 2 \mathrm{H}), 7.56$ (m, 2H), $7.65(\mathrm{~m}, 2 \mathrm{H}), 7.93(\mathrm{~m}, 6 \mathrm{H}), 8.10(\mathrm{~m}, 2 \mathrm{H})$; ${ }^{13} \mathrm{C}$ NMR $\left(300 \mathrm{MHz}, \mathrm{CDCl}_{3}\right): \delta 13.47,18.70,31.28$, $69.30,115.97,117.15,120.56,123.02,126.00$, $126.84,127.23,128.20,129.31,129.54,130.22$, $131.88,134.01,135.87,141.00,155.04,164.45$; $v_{\max }$ $(\mathrm{KBr}) / \mathrm{cm}^{-1}:$ 3027.0, 2954.4, 2929.3, 2869.1, 1604.7, $1585.4,1492.4,1463.2,1270.3,1241.0,1218.4$, 1066.0, 1028.0, 960.5 .

\section{RESULTS AND DISCUSSION}

\section{Syntheses of the Monomers}

$(R)$ and $(S)$-1, 1'-binaphthol were resolved from racemic $1,1^{\prime}$-binaphthol by $(8 S, 9 R)-(-)-N$-benzylcinchonidinium chloride according to the literature, both enantiomers could be obtained with $90 \%$ yield and $>99.9 \%$ e.e. ${ }^{26,27}(S)$-M-1 and $(R)$-M-1 were synthesized from $(S)$ and $(R)$-BINOL (Scheme 1) respectively according to the literature. ${ }^{13,28}(S)$-M-1 and $(R)$-M1 served as the monomers for the synthesis of the desired chiral polymers. They can also be used as the starting materials or building blocks to prepare the novel chiral catalysts, molecular recognition and the polarized light-emitting sensors. Attachment of the butoxy substitutents on binaphthyl rings as side chain of the polymers cannot only modify the electronic properties and conjugated structure of chiral polymers, but can also dramatically improve solubility in organic solvents and convenient processability for electro-optical sensors. ${ }^{16,29-33}$

The syntheses of the two divinyl conjugated monomers $\mathbf{M - 2}$ and $\mathbf{M - 3}$ were carried out in a very mild condition by Wittig reaction. $\mathbf{M}-\mathbf{2}$ and $\mathbf{M}-3$ were stable in the air, but it should be kept in heptane at $-4{ }^{\circ} \mathrm{C}$ before using. M-2 could be obtained from the starting 


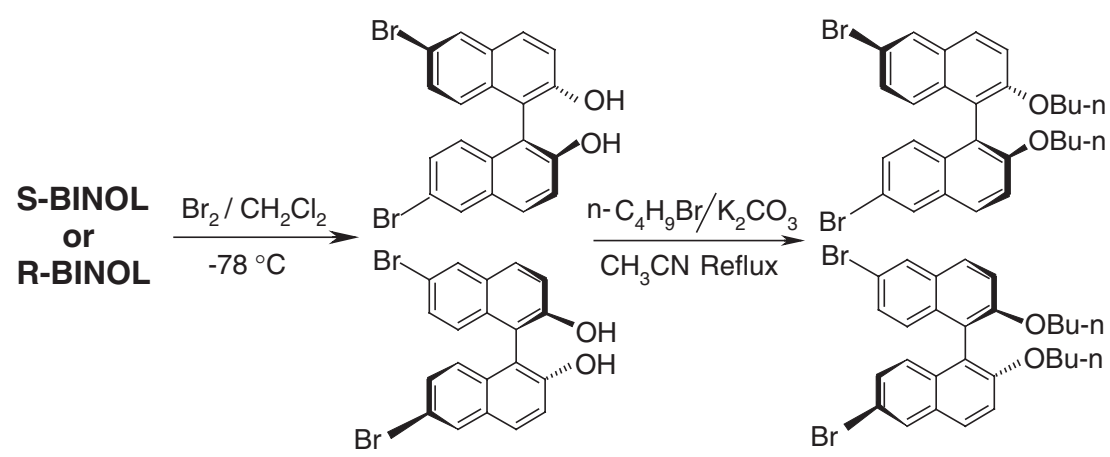

(S)-M-1 or $(R)-\mathrm{M}-1$

Scheme 1. Synthesis procedures of the monomer $(S)-\mathbf{M}-\mathbf{1}$ and $(R)-\mathbf{M}-\mathbf{1}$.

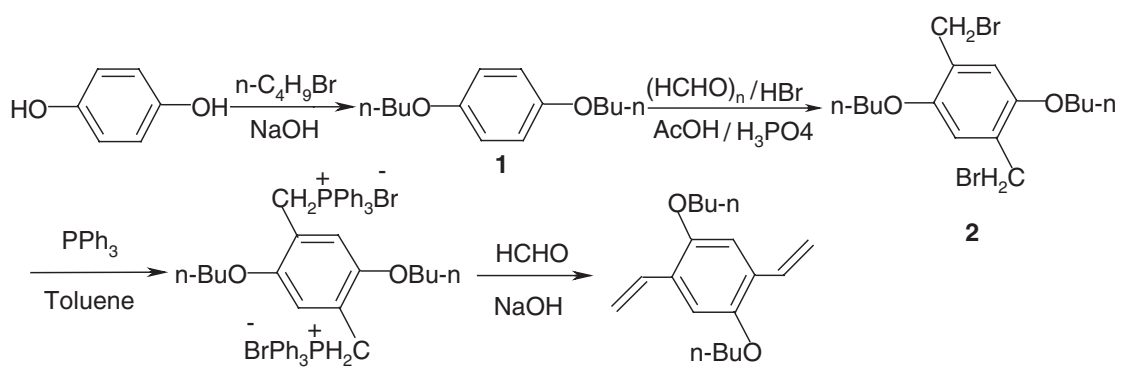

M-2
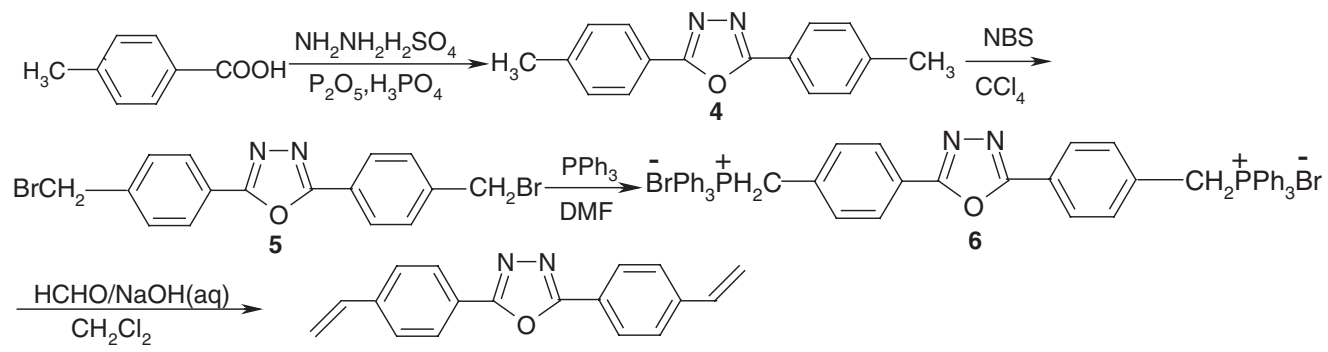

M-3

Scheme 2. Synthesis procedures of the monomers M-2 and M-3.

products of 1,4-hydroquinone (Scheme 2). The synthesis routes of 1-3 were carried out according to the literature. ${ }^{34,35} \mathbf{M}-\mathbf{3}$ was synthesized by the starting products $p$-toluic acid (Scheme 2), and 4-6 were obtained according to the literature. ${ }^{36,37}$ Bisphosphonium salts of $\mathbf{6}$ in refluxing toluene failed due to the poor solubility of the two salts. It only afforded the monophosphonium salts in the form of a white precipitate in a quantitative yield. Normally DMF was chosen as solvent. But 3 must be prepared in toluene because dibutoxy group can lead to higher solubility in DMF solution.

\section{Syntheses of the Polymers}

A typical Heck reaction condition was applied to the polymerization. The $\mathrm{C}-\mathrm{C}$ cross coupling process was easily carried out in DMF in the presence of a catalytic amount $(2 \% \mathrm{~mol})$ of $\mathrm{Pd}(\mathrm{OAc})_{2}$ with $\mathrm{Et}_{3} \mathrm{~N}$ and triphenylphosphate under a $\mathrm{N}_{2}$ atomsphere. The poly- merization went on quickly in a good yield. Instead of the Wittig method, the Heck synthetic route was used for the preparation of the chiral polymers because the Heck reaction directly produced the desired polymers with trans configuration. ${ }^{38-43} \mathrm{Pu}$ also studied the Heck coupling of the chiral binaphthyl monomers with the divinyl monomers. GPC analysis results of polymers indicated that neither the halogen atoms nor the size of the alkyl groups in the binaphthyl monomers had effect on the molecular weight of the polymers. ${ }^{44}$ In this paper, four chiral conjugated polymers were obtained by the polymerization of $(S)$-6, $6^{\prime}$-dibromo2,2'-bisbutoxy-1,1'-binaphthyl ((S)-M-1) and $(R)$ 6,6'-dibromo-2,2'-bisbutoxy-1,1'-binaphthyl ( $R$ - $-\mathbf{M}$ 1) with 1,4-divinyl-2,5-dibutoxyenzene (M-2) and 1,3,4-oxadiazole-2,5-bis(4-vinylbenzene) (M-3) under Pd-catalyzed Heck reaction respectively (Scheme 3). Four polymers are stable in air and show good solubility in THF, $\mathrm{CH}_{2} \mathrm{Cl}_{2}, \mathrm{CHCl}_{3}$, DMF. GPC analysis and 


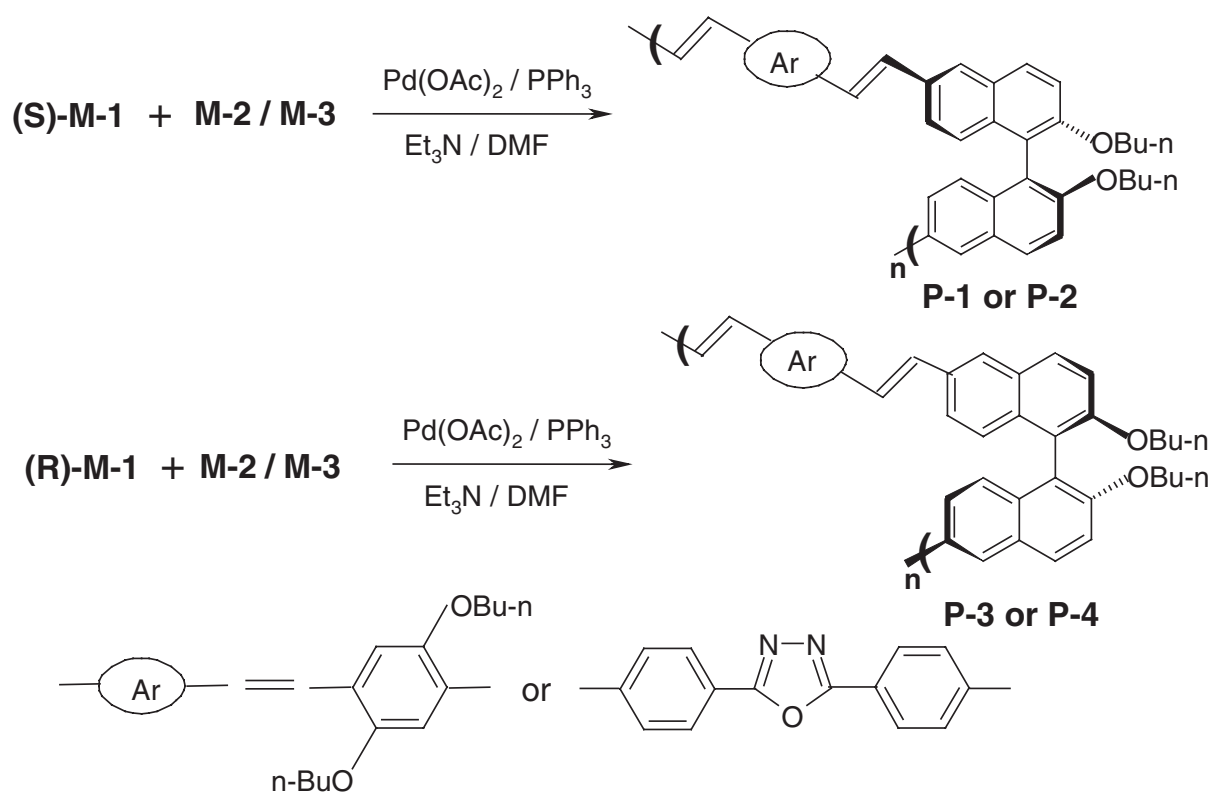

Scheme 3. Synthesis of the polymers P-1, P-2, P-3 and P-4.

Table I. GPC analysis and specific optical rotation of four polymers

\begin{tabular}{rrrcc}
\hline & $M_{\mathrm{w}}$ & $M_{\mathrm{n}}$ & PDI & $\begin{array}{c}\text { Optical rotation }[\alpha]^{25} \mathrm{D} \\
(c=0.5, \mathrm{THF})\end{array}$ \\
\hline $\mathrm{P}-1$ & 7900 & 5400 & 1.46 & +358 \\
$\mathrm{P}-2$ & 7200 & 4200 & 1.71 & +283 \\
$\mathrm{P}-3$ & 10360 & 5630 & 1.84 & -345 \\
$\mathrm{P}-4$ & 11200 & 4500 & 2.49 & -373 \\
\hline
\end{tabular}

the specific optical rotation results of four polymers were listed in the Table I. The rigid structure and $\mathrm{C}_{2}$ symmetry of the chiral binaphthyl molecules play important role in chiral induction. The chirality of binaphthyl compounds is derived from the restricted rotation of the two naphthalene rings. The dihedral angle between two naphthalene rings of a binaphthyl molecule ranges from 60 to $120^{\circ}$. Four chiral polymers are made of optically pure binaphthyl units, when the divinyl conjugated monomers $\mathbf{M - 2}$ and M-3 are assumed to be coplanar, a helical structure should be generated. This kind chiral configuration of binaphthyls is remarkably stable. ${ }^{5,16,30,44}$

\section{UV Absorption Spectra}

UV spectra of monomers and polymers were determined in $\mathrm{CH}_{2} \mathrm{Cl}_{2}$ solution. UV spectra of polymers P-1, P-3 and polymers $\mathbf{P}-\mathbf{2}$ and $\mathbf{P}-\mathbf{4}$ are similar. Compared to monomers, both polymers' UV absorption spectra displayed great red shifts. The strongest absorption wavelength $\lambda_{\max }$ of $\mathbf{P}-\mathbf{1}$ and $\mathbf{P}-\mathbf{3}$ appeared at the region from 380 to $480 \mathrm{~nm}$ (Figure 1), and $\mathbf{P - 2}$ and P-4 are in the region from 340 to $420 \mathrm{~nm}$ (Figure 2). It can be concluded that there is a large

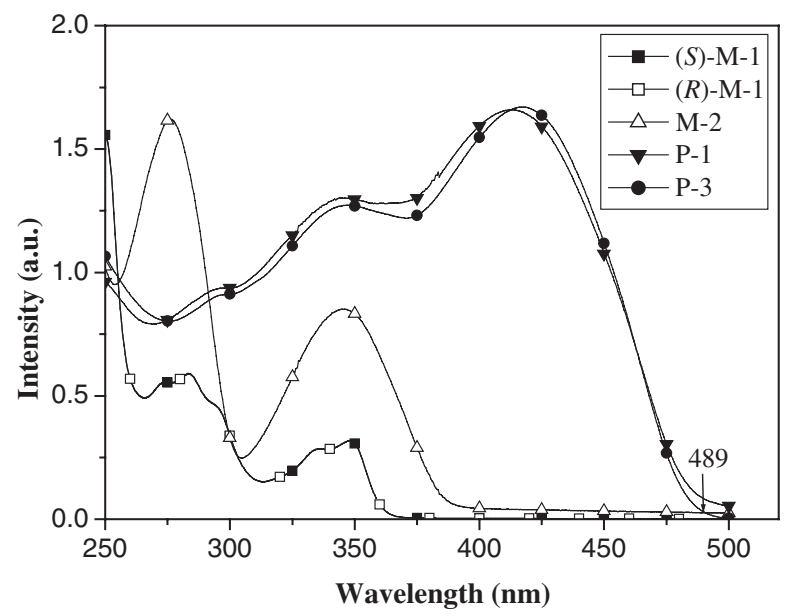

Figure 1. UV spectra of (S)-M-1, $(R)-\mathbf{M}-1, \mathbf{M}-2, \mathbf{P}-1$ and P-3.

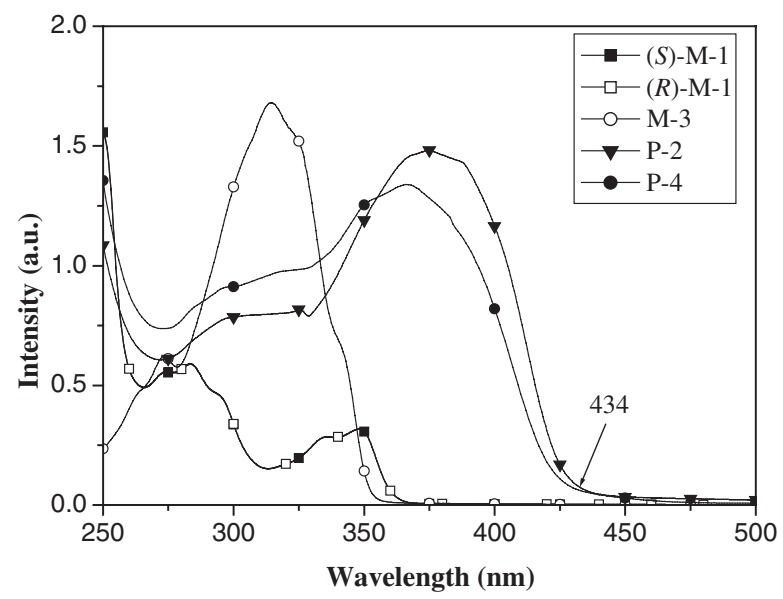

Figure 2. UV spectra of (S)-M-1, $(R)-\mathbf{M}-1, \mathbf{M}-3, \mathbf{P}-2$ and P-4. 
red-shift in the electronic absorptions of the conjugated polymers due to the effective $\pi-\pi^{*}$ conjugated segment of the divinyl conjugated unit and naphthyl group in the main chain. ${ }^{5,8}$

The absorption spectra edge of $\mathbf{P}-\mathbf{1}, \mathbf{P}-\mathbf{3}$ and $\mathbf{P}-\mathbf{2}, \mathbf{P}-$ 4 were onset at 489 and $434 \mathrm{~nm}$, which corresponded to band gaps at 2.54 and $2.80 \mathrm{eV}$ respectively..$^{19,45}$ The band gap of P-2 and P-4 is larger than P-1 and P-3, it can be mainly ascribed to well extended conjugation of P-1 and P-3 between the repeated units. The $\sigma$ band between the 1,3,4-oxdiazole unit and the phenyl unit will affect the conjugation effect of P-2 and P-4. The larger red shift of UV spectra of $\mathbf{P}-\mathbf{1}$ and $\mathbf{P}-\mathbf{3}$ can also be attributed to the electron-donating effect of the butoxy-substituted moiety of M-2 and the better coplanarity chain structure.

\section{Fluorescence Spectra}

The fluorescent spectra of the four polymers in THF solution and in solid phase were shown in Figure 3 and Figure 4. The fluorescent spectra of polymers $\mathbf{P}$ 1, P-3 and polymers P-2 and P-4 are almost similar due to the same chain structure except chiral center units. The polymers can emit very strong green-blue light under Ultraviolet light $(366 \mathrm{~nm})$ or sunlight even in the very low concentration. (S)-M-1 and $(R)$-M-1 cannot show visible fluorescence, and fluorescent wavelengths of M-2 and M-3 appeared at 383 and $389 \mathrm{~nm}$ respectively. The fluorescent intensity and wavelengths of the four polymers were dramatically increased over that of the monomers $\mathbf{M}-\mathbf{2}$ and $\mathbf{M}-\mathbf{3}$, the maximum fluorescent wavelengths $\lambda_{\max }^{\mathrm{F}}$ of $\mathbf{P - 1}$ and $\mathbf{P - 3}$ in THF solution showed two photoluminescent bands at $464,487 \mathrm{~nm}$ and $460,485 \mathrm{~nm}$, and P2, P-4 showed 452 and $462 \mathrm{~nm}$. The four polymers showed strong green-blue fluorescence due to the efficient energy migration from the extended $\pi$-electronic

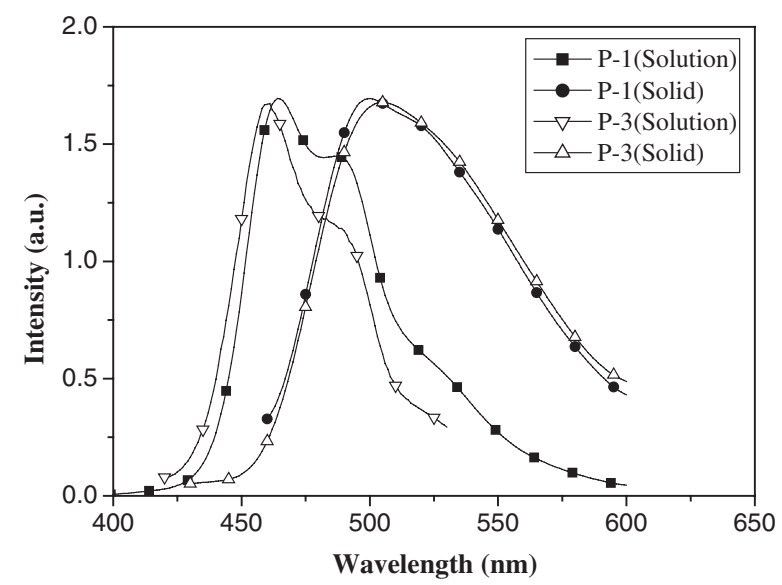

Figure 3. Fluorescence spectra of P-1 and P-3 (P-1: Solution, $\lambda_{\mathrm{ex}}=436 \mathrm{~nm}$; Solid, $\lambda_{\mathrm{ex}}=440 \mathrm{~nm}$. P-2: Solution, $\lambda_{\mathrm{ex}}=432 \mathrm{~nm}$; Solid, $\lambda_{\mathrm{ex}}=438 \mathrm{~nm}$ ).

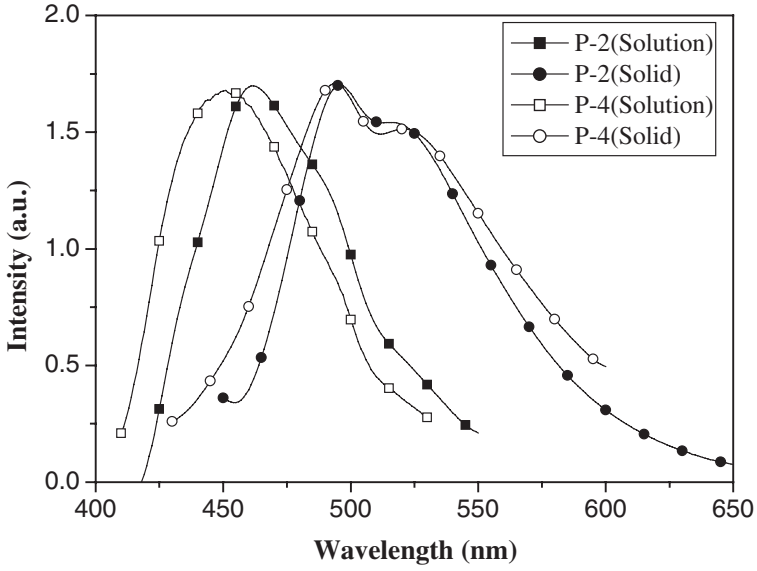

Figure 4. Fluorescence spectra of P-2 and P-4 (P-2: Solution, $\lambda_{\mathrm{ex}}=425 \mathrm{~nm}$; Solid, $\lambda_{\mathrm{ex}}=442 \mathrm{~nm}$. P-4: Solution, $\lambda_{\mathrm{ex}}=422 \mathrm{~nm}$; Solid, $\lambda_{\mathrm{ex}}=440 \mathrm{~nm}$ ).

structure of the conjugated polymer main to the chiral binaphthyl core. ${ }^{5,8,17,43}$ But in the solid powder state, the fluorescent wavelength $\lambda_{\max }^{\mathrm{F}}$ of $\mathbf{P}-\mathbf{1}$ and $\mathbf{P}-\mathbf{3}$ appeared red shift to $500 \mathrm{~nm}$, while $\mathbf{P - 2}$ and $\mathbf{P}-\mathbf{4}$ had a larger red shift to 496 and $519 \mathrm{~nm}$. It can be attributed to more planar conformations of conjugated chains in the solid state than in solution. ${ }^{43,46,47}$ The greatly enhanced fluorescence of chiral conjugated polymers are expected to have potential application in the polarized light-emitting molecular sensor.

\section{Spectra}

Although the optical rotation values $\left([\alpha]^{25}{ }_{\mathrm{D}}\right)$ of monomers $(S)$-M-1 and $(R)$-M-1 are -19.5 and +18.8 , their conjugated polymers of P-1, P-2, P-3 and $\mathbf{P}-\mathbf{4}$ are $+358,+283,-345$ and -373 respectively. The absolute values of the optical rotation $\left([\alpha]^{25}{ }_{\mathrm{D}}\right)$ of four polymers are much larger than the monomers $(S)$-M-1 and $(R)$-M-1. Both monomers $(S)$-M-1, $(R)$ M-1 and four polymers exhibit stronger CD signals with positive and negative Cotton Effects in their CD spectra (Figures 5-7). Monomers $(S)$-M-1, $(R)$ M-1 and polymers P-1, P-3 and polymers P-2, P-4 have opposite signs for their optical rotation and $C D$ spectra, but their position and intensity is almost identical. The molecular ellipticity of $(S)-\mathbf{M}-\mathbf{1}$ is: $[\theta]_{\lambda}=-8.63 \times 10^{5}(232 \mathrm{~nm}),+1.08 \times 10^{6}(245 \mathrm{~nm})$, $-6.47 \times 10^{4}(290 \mathrm{~nm})$, and the molecular ellipticity of $(R)$-M-1 is: $[\theta]_{\lambda}=+8.84 \times 10^{5}(232 \mathrm{~nm}),-1.06 \times$ $10^{6}(245 \mathrm{~nm}),+7.35 \times 10^{4}(290 \mathrm{~nm})$. The molecular ellipticity of P-1 is: $[\theta]_{\lambda}=-3.62 \times 10^{5}(234 \mathrm{~nm})$, $+2.15 \times 10^{5} \quad(271 \mathrm{~nm}), \quad-1.91 \times 10^{4} \quad(346 \mathrm{~nm})$, $+2.86 \times 10^{4}(417 \mathrm{~nm})$, the molecular ellipticity of P-2 is: $[\theta]_{\lambda}=-4.32 \times 10^{5}(233 \mathrm{~nm}),+2.89 \times 10^{5}$ $(250 \mathrm{~nm}), \quad+4.88 \times 10^{4} \quad(312 \mathrm{~nm}), \quad-5.60 \times 10^{4}$ $(354 \mathrm{~nm}),+8.59 \times 10^{4}(392 \mathrm{~nm})$, the molecular ellipticity of $\mathbf{P - 3}$ is: $[\theta]_{\lambda}=+3.40 \times 10^{5}(234 \mathrm{~nm})$, 


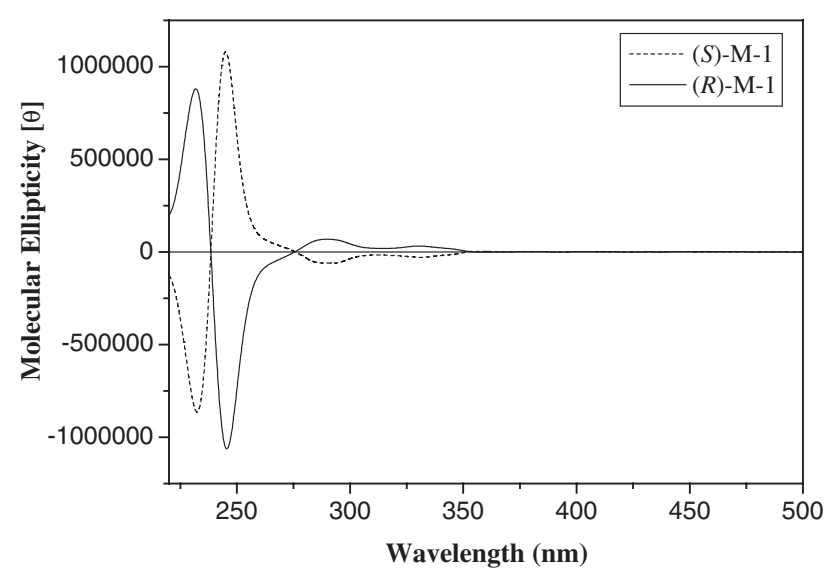

Figure 5. CD spectra of (S)-M-1 and (R)-M-1 (in THF).

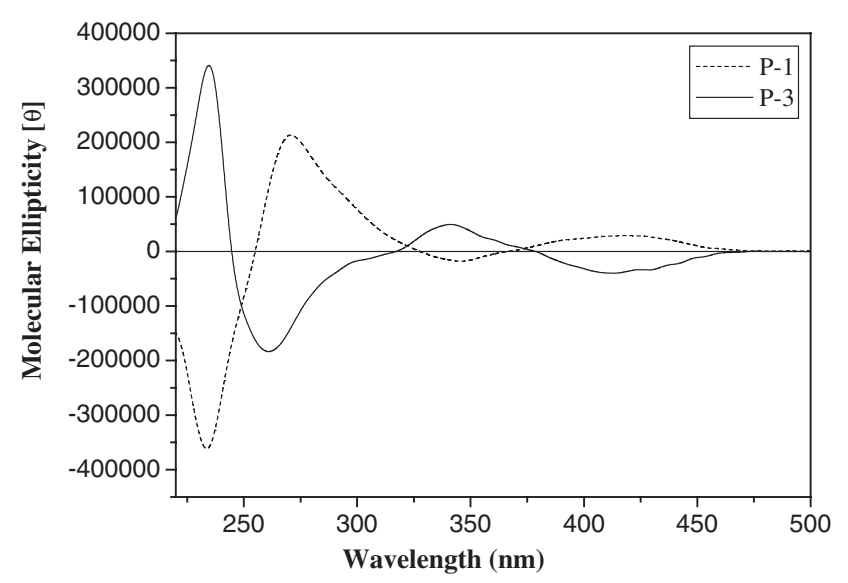

Figure 6. CD spectra of $\mathbf{P}-\mathbf{1}$ and $\mathbf{P}-\mathbf{3}$ (in THF).

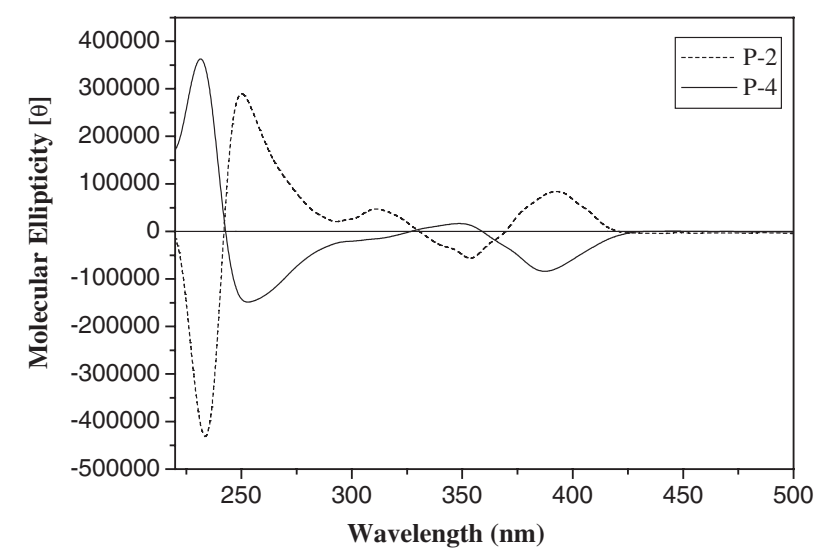

Figure 7. CD spectra of $\mathbf{P}-\mathbf{2}$ and $\mathbf{P}-\mathbf{4}$ (in THF).

$-1.84 \times 10^{5} \quad(261 \mathrm{~nm}), \quad+4.88 \times 10^{4} \quad(342 \mathrm{~nm})$, $-4.10 \times 10^{4}(417 \mathrm{~nm})$, and the molecular ellipticity of P-4 is: $[\theta]_{\lambda}=+3.62 \times 10^{5}(231 \mathrm{~nm}),-1.49 \times$ $10^{5}(253 \mathrm{~nm}),-1.69 \times 10^{4}(312 \mathrm{~nm}),+1.62 \times 10^{4}$ $(348 \mathrm{~nm}),-8.32 \times 10^{4}(388 \mathrm{~nm})$. The long wavelengths $\mathrm{CD}$ effect of polymers can be regarded as the more extended conjugated structure in the polymer chain. Cotton effect of the CD spectra of four polymers are consistent with their UV absorption position. ${ }^{7,48,49}$

\section{CONCLUSIONS}

Pd-catalyzed Heck reaction was found to offer a simple access to the four chiral polymers. Four chiral polymers can emit very strong green-blue fluorescence even in very low concentration. The polymer showed strong green-blue fluorescence due to the efficient energy migration from the extended $\pi$-electronic structure of the conjugated polymer main to the chiral binaphthyl core. There exists greatly difference from fluorescence spectra in the solid and solution state. The polymers exhibit stronger CD signals with positive and negative Cotton Effect in its CD spectra. The major differences between monomers and polymers are that a long wavelength Cotton Effect is observed for the polymer due to its more extended conjugation. Cotton effect of the CD spectra of four polymers are consistent with their UV absorption position.

Acknowledgment. This research program was supported by the National Natural Science Foundation of China (No. 20474028) and Jiangsu province Nature Science Foundation in China (No. BK2004086).

\section{REFERENCES}

1. K. Shinohara, S. Yasuda, G. Kato, and H. Shigekawa, J. Am. Chem. Soc., 123, 3619 (2001).

2. J. P. Lere-Porte, J. J. E. Moreau, F. Serein-Spirau, and S. Wakim, Tetrahedron Lett., 42, 3073 (2001).

3. Q. Liu, G. Yu, A. K. Y. Jen, Q. S. Hu, and L. Pu, Macromol. Chem. Phys., 203, 37 (2002).

4. H. C. Zhang and L. Pu, Tetrahedron, 59, 1703 (2003).

5. L. Pu, Chem. Rev., 98, 2405 (1998).

6. D. Wang, T. J. Liu, and W. C. Zhang, Chem. Commun., 1747 (1998).

7. H. F. Chow and M. K. Ng, Tetrahedron: Asymmetry, 7, 2251 (1996).

8. Y. Meng, T. S. Williams, D. Wang, T. J. Liu, H. F. Chow, and C. J. Li, Tetrahedron: Asymmetry, 9, 3693 (1998).

9. V. Pugh, Q. S. Hu, X. B. Zuo, F. D. Lewis, and L. Pu, J. Org. Chem., 66, 6136 (2001).

10. Q. S. Hu, W. S. Huang, and L. Pu, J. Am. Chem. Soc., 119, 12454 (1997).

11. H. B. Yu, Q. S. Hu, and L. Pu, J. Am. Chem. Soc., 122, 6500 (2000).

12. D. Moore and L. Pu, Org. Lett., 4, 1855 (2002).

13. D. Simonson, K. Kingsbury, M. H. Xu, Q. S. Hu, M. Sabat, and L. Pu, Tetrahedron, 58, 8189 (2002).

14. M. H. Xu, J. Lin, Q. S. Hu, and L. Pu, J. Am. Chem. Soc., 124, 14239 (2002).

15. H. B. Yu, X. F. Zheng, Z. M. Lin, Q. S. Hu, W. S. Huang, and L. Pu, J. Org. Chem., 64, 8149 (1999). 
16. Q. S. Hu, D. Vitharana, and L. Pu, Macromolecules, 29, 1082 (1996).

17. H. J. Deussen, E. Hendrickx, and C. Boutton, J. Am. Chem. Soc., 118, 6841 (1996).

18. S. V. Elshocht, T. Verbiest, L. Ma, H. Cheng, K. Y. Musick, and L. Pu, Chem. Phys. Lett., 309, 315 (1999).

19. A. K. Y. Jen, Y. Liu, Q. S. Hu, and L. Pu, Appl. Phys. Lett., 75, 3745 (1999).

20. L. Zheng, R. C. Urian, Y. Liu, A. K. Y. Jen, and L. Pu, Chem. Mater., 12, 13 (2000).

21. W. L. Yu, H. Meng, J. Pei, W. Huang, Y. F. Li, and A. J. Heeger, Macromolecules, 31, 4838 (1998).

22. Y. M. Sun, Polymer, 42, 9495 (2001).

23. M. Meer, E. Buchwald, S. Karg, W. Riess, and M. Greczmiel, Synth. Met., 76, 95 (1996).

24. Z. H. Peng, Z. N. Bao, and M. E. Galvin, Adv. Mater., 10, 680 (1998).

25. S. W. Hwang and Y. Chen, Macromolecules, 35, 5438 (2002).

26. K. Tanaka, T. Okada, and F. Toda, Angew. Chem., Int. Ed., 32, 1147 (1993).

27. D. Cai, D. L. Hughes, T. R. Verhoeven, and P. J. Reider, Tetrahedron Lett., 36, 7991 (1995).

28. D. J. Cram, R. C. Helgeson, K. Koga, E. P. Kyba, and L. R. Sousa, J. Org. Chem., 43, 2758 (1978).

29. L. Ma, Q. S. Hu, and L. Pu, Tetrahedron: Asymmetry, 7, 3103 (1996).

30. L. Ma, Q. S. Hu, D. Vitharana, C. Wu, C. M. S. Kwan, and L. Pu, Macromolecules, 30, 204 (1997).

31. K. Y. Musick, Q. S. Hu, and L. Pu, Macromolecules, 31, 2933 (1998).

32. Q. S. Hu, D. Vitharana, G. Y. Liu, V. Jain, and L. Pu, Macromolecules, 29, 5075 (1996).
33. L. Ma, Q. S. Hu, K. Y. Musick, D. Vitharana, C. Wu, C. M. S. Kwan, and L. Pu, Macromolecules, 29, 5083 (1996).

34. J. Eldo, E. Arunkumar, and A. Ajayaghosh, Tetrahedron Lett., 41, 6241 (2000).

35. A. Helms, D. Heiler, and G. Mclendon, J. Am. Chem. Soc., 114, 6227 (1992).

36. J. X. Zhang, Y. P. Cui, and M. L. Wang, Chem. Lett., 824 (2001).

37. S. G. Yin, J. B. Peng, and C. X. Li, Synth. Met., 93, 193 (1998).

38. A. Meijere and F. E. Meyer, Angew. Chem., Int. Ed., 33, 2379 (1994).

39. M. Pan, Z. N. Bao, and L. P. Yu, Macromolecules, 28, 5151 (1995).

40. K. L. Paik, N. S. Baek, H. K. Kim, and H. H. Lee, Polym. Prepr., 43, 77 (2002).

41. W. You, L. M. Wang, Q. Wang, and L. P. Yu, Macromolecules, 35, 4636 (2002).

42. U. Scherf and K. Mullen, Synthesis, 1-2, 23 (1992).

43. Y. X. Cheng, T. D. Liu, and L. W. Chen, Chin. J. Polym. Sci., 22, 327 (2004).

44. H. C. Zhang and L. Pu, Tetrahedron, 59, 1703 (2003).

45. P. Jian, L. Y. Wang, N. Jing, and W. Huang, Macromolecules, 34, 7241 (2001).

46. J. P. Lere-Porte, J. J. E. Moreau, F. Serein-Spirau, C. Torreilles, and A. Righi, J. Mater. Chem., 10, 927 (2000).

47. H. Li, D. R. Powell, T. K. Firman, and R. West, Macromolecules, 31, 1093 (1998).

48. C. Hua, L. Ma, and L. Pu, Tetrahedron: Asymmetry, 7, 3083 (1996).

49. C. Hua and L. Pu, Macromol. Chem. Phys., 200, 1274 (1999). 